\title{
Gallup StrengthsFinder in Engineering
}

\section{Dr. Brenda Read-Daily, Elizabethtown College}

Dr. Brenda Read-Daily is an Assistant Professor of Engineering at Elizabethtown College in Pennsylvania. She holds a BS in Civil Engineering from Bradley University, and a MS and PhD in Environmental Engineering from the University of Notre Dame.

\section{Dr. Kurt M. DeGoede, Elizabethtown College}

Professor of Engineering and Physics, Elizabethtown College. His research interests in biomechanics include developing clinical instruments for rehabilitation. Dr. DeGoede teaches upper-level undergraduate mechanical engineering and design courses and the first-year introduction to engineering course. $\mathrm{He}$ is also developing a collaborative study abroad program in West Africa built around social enterprise initiatives.

\section{Stacey L. Zimmerman, Elizabethtown College}

Stacey Zimmerman is a Gallup-certified strengths coach who believes in the powerful combination of honoring our natural talents while uncovering our unique purpose in life. She currently directs strengths education, coaching, and leadership development at Elizabethtown College, and she was a former human resources professional. Through the lens of strengths and leadership development, she is able to mentor and coach individuals with the goal of living authentic lives. 


\section{Abstract \\ Gallup StrengthsFinder in Engineering}

The Gallup StrengthsFinder $\circledR$ Inventory identifies individual's top-five Strengths from the 34 themes in the inventory [1]. Strengths such as Activator, Deliberative, and Restorative are grouped into four domains: executing, influencing, relationship building and strategic thinking.

All of our first-year students at Elizabethtown College complete the Strengths Inventory. Throughout the two-semester Introduction to Engineering (ItE) course sequence, we contextualize Strengths for engineering students by contrasting strengths and skills. We use the StrengthsFinder to capture personal strengths and define engineering skills through the lens of the ABET a-k outcomes. We frame developing the required engineering skills from the foundation of their individual strengths. Our "One-Minute Engineer" assignment requires students to describe why they are pursuing engineering as a career path. Again, the framework of StrengthsFinder helps students clearly express their motivations.

Team projects form the framework for ItE course sequence. We sort students into teams with diverse Strengths [2]. Students utilize team contracts in which they develop team roles based on individual Strengths [3]. A team mapping exercise reveals that our engineering students tend to overpopulate the executing and strategic thinking domains of Strengths. Less stereotypical engineering students with Strengths in relationship building and influencing realize their position to uniquely contribute in areas that are often undervalued in student engineering teams.

This paper will examine our use of Gallup StrengthsFinder as a case study. Additionally, we compare the distribution of Strengths among our engineering students to those college-wide and at engineering students at MacEwan University. We found that using this approach helps students capitalize on unique strengths, build more diverse teams, foster student confidence, and fight imposter syndrome.

\section{Introduction and Background}

Introduction to Engineering students often struggle to sort out peer-to-peer roles in team assignments. They tend to default to the familiar "club structure" with roles of president, vice president, secretary, and treasurer. While this structure may have worked well in their previous group experiences, it is often inappropriate in the context of engineering projects. These observations inspired us to find creative ways of helping the students assign team roles and better understand how their unique attributes can contribute to their team projects. We used a MyersBriggs tool to help students better understand themselves and the others working on their project team.

Then ten years ago, Elizabethtown College began to use Gallup's Clifton StrengthsFinder (CSF), an online assessment that identifies personal talents, with selected groups of students, faculty, and staff. The results were positive, and the college started having all incoming students take the StrengthsFinder Inventory as a part of summer orientation. 
The College now utilizes this inventory across campus, as well as the principles of Strengthsbased education [5], to build self-awareness in students, faculty, and staff. Personal development is based on the belief that everyone has natural talents, and our responsibility as educators is to help our students develop, both personally and professionally, based on those talents. In 2016, the College began offering every incoming first-year student the opportunity to take the inventory. Strengths education programming occurs during orientation, through leadership programs, in the residence halls, and in the curriculum.

\section{Background on Gallup StrengthsFinder}

Strengths philosophy is grounded in positive psychology and began with Dr. Donald Clifton asking the question, "What would happen if we studied what is right with people?" This question led to research and interviews that culminated in the creation of the Clifton StrengthsFinder [4]. Strengths are built on the equation of starting with natural talent, adding in skills, knowledge, and practice, and resulting in a strength (the ability to consistently provide near-perfect performance in a specific task) [4]. As evidenced by this equation, strengths and skills are not the same. Both are a necessary part of the equation to reach success. As an institution we seek to highlight and enhance the talents, skills, and knowledge of our students to best prepare them for their future lives.

Understanding individual strengths is a key component of self-awareness; utilizing strengths in team development creates a common language to help understand the importance of each individual on the team. In the team setting, individuals can do what they do best by capitalizing on their strengths while allowing other team members to focus on their areas of strength, which likely vary with each individual [5]. This creates a well-rounded team where each individual brings unique strengths that benefit the team. While the 34 themes of talents are most useful for self-awareness, Gallup has created four domains of Strengths that elevate team development [4]. Research has shown that teams with Strengths from each domain are cohesive and able to communicate well [6] [7].

Other tools that are helpful in developing self-awareness are the Myers-Briggs Type Indicator (MBTI), the DiSC profile, and the Kolb Learning Style Inventory. These inventories all measure different aspects of an individual; CSF measures natural talent, MBTI measures preferred modes of psychological processing, DiSC measures behavioral style, and Kolb measures individual learning styles [8]. Our campus chose to utilize the CSF as our primary tool because of Gallup's specific focus on college students with their StrengthsQuest platform. This platform utilizes the same inventory (CSF), but the information provided after taking the inventory is geared toward students.

Within the Engineering education community, MBTI has been widely used in team formation [9]. Others report using StrengthsFinder Inventory in engineering programs including first-year engineering courses [10] [11] [12], an upper-level engineering course promoting leadership development [13], and a masters-level engineering management course [7]. A previous study using Strengths with a population of first-year engineering students at Grant MacEwan University in Edmonton, Alberta compared the Strengths found in their students with the overall 
data from the overall population in 2010 [14]. We compare our engineering students with this data and the averages for all US college students [15] below.

Our use of Strengths in engineering curriculum

In the context of its wide use on our campus, we felt that replacing our use of Myers-Briggs with the CSF framework would enhance our ability to mentor students to feel more confident about their ability to contribute to their teams, value the talents of their teammates, and avoid defaulting to stereotypical roles. For our Engineering students we work to instill an understanding of the CSF Strengths as natural talents. From this position of personal strength all students develop the required engineering skills, as defined through the lens of the ABET a-k learning outcomes. As each student possesses unique strengths, they will find a unique path to mastering the skills required for engineering practice.
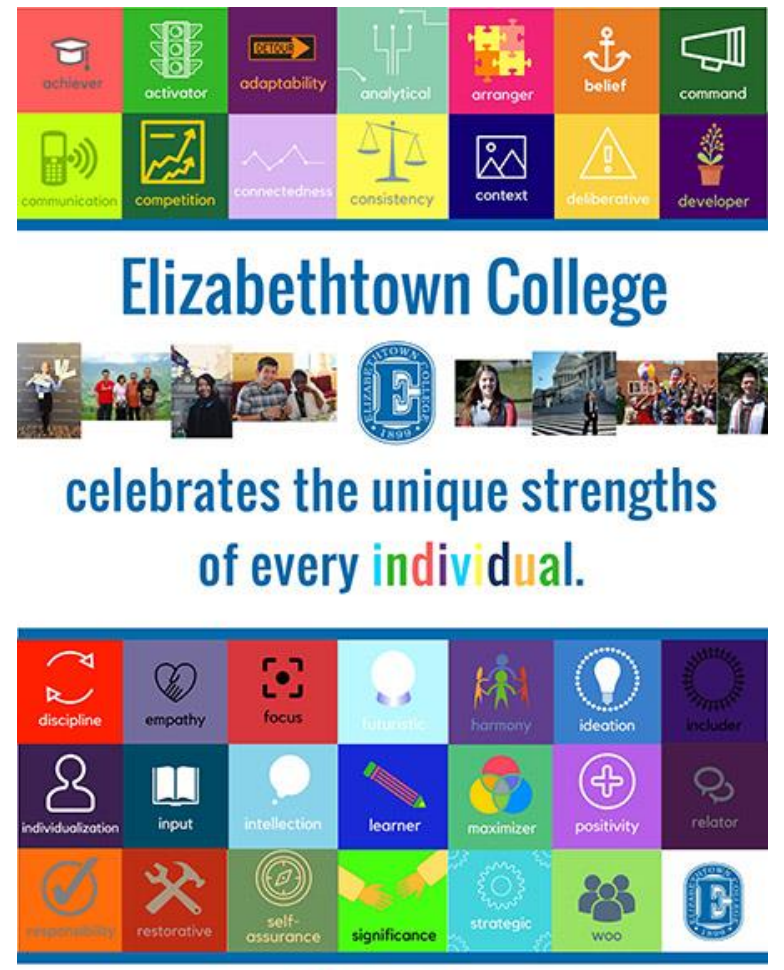

Stren $\mathrm{t} / \mathrm{s}$

We've all got them. Discover yours with

CliftonStrengths

Figure 1: Strengths poster displayed in department commons.

We were motivated to integrate Strengths into our Curriculum because we wanted to foster a culture that celebrates the diversity of Strengths among our students. Figure 1 shows a poster in a student common area to remind students of the value of their strengths. In particular, we felt that having students understand their own strengths and the strengths of their classmates we could (1) bolster community and fight imposter syndrome (2) improve students' self-awareness, and (3) help students understand how to leverage their Strengths in their work as engineers. We 
seek to improve and develop the skills students need to be successful engineers. However, we wanted to move away from a mindset of "strengthen your weakness." The StrengthsFinder approach helps students embrace their innate personalities. Then from that position of strength, the students develop the skills needed as an engineer. They develop weak skills, not weak personality traits (Strengths).

\section{ItE course sequence}

The activities described in this paper were implemented over two years within an Introduction to Engineering (ItE) course sequence at Elizabethtown College. The Engineering and Physics Department offers ABET-accredited BS degree in Engineering and Computer Engineering. The ItE course sequence consists of Introduction to Engineering I in the fall followed by Introduction to Engineering II in the spring. Both engineering and computer engineering majors are required to take the ItE sequence. Enrollment is typically about 50 students:

- Fall 2016 (58 students)

- $\quad$ Spring 2017 (47 students)

- Fall 2017 (47 students)

- $\quad$ Spring 2018 (48 students).

Each semester teams of four or five students are formed using CATME Team-Maker (described in the next section) with students working on the same teams for the duration of each semester. The course includes both individual and team-based assignments. Course topics include

- the engineering discipline and sub-disciplines project management and teamwork

- the design process

- ethics

- technical writing and presentations

- engineering tools: CAD, MATLAB

- statistics

- professional development, and

- technical research.

- StrengthsFinder is used directly in assignments connected to the engineering discipline, project management, and teamwork.

Students completed the StrengthsFinder Inventory during summer orientation. During the first week of class, they received additional instruction on understanding their top-five Strengths from the Gallup-Certified Strengths Coach on our campus. The students then completed a team formation survey CATME Team-Maker software that required them to enter their top-five Strengths. Semester-long teams were formed by the second week.

\section{Course Assignments}

\section{Team formation using CATME Team-Maker}

Engineering project teams are formed using CATME's Team-Maker tool [2] [16]. At the start of the semester, students complete a survey administered through CATME. The survey questions span a variety of topics important for successful teams: demographics and scheduling, engineering ABET skills, commitment level, top-five Strengths, and Strength Domains. The 
results are sorted and weighted according to the importance-level of the specific topic. Within some categories, more diverse teams are preferred such as in the case of Strength Domains. In other cases, less diversity is preferred as in the case of commitment-level. The instructors of the courses continued the sorting process to make sure that each of the four talent domains was represented on each team.

\section{Team contract}

In all of our engineering project courses, students are required to complete team contracts [3] [17]. Team contracts are used to assign team member roles and responsibilities, determine communication methods, and strategize methods for conflict resolution. Teams were not explicitly told to consider their team member's Strengths in the assignment's prompts. However, students were asked to share their Strengths with each other by completing the Team Talent Map [18]. They also reviewed "Working with others who have [X]" excerpts for each of the Strengths of their teammates [1]. After completing these activities, students complete the team contract including the prompts:

As a team, identify for each member the leadership or backup responsibilities for which this person is accountable to the team. (a) Please describe in 50 to 100 words your rationale for selecting areas and individuals to lead areas. (b) Please assign each member to important roles and identify key responsibilities of each role.

\section{One-Minute Engineer}

Throughout the Introduction to Engineering I course, students explore the field of engineering and consider their reasons for pursuing an engineering major. The One-Minute Engineer is a three-part assignment where students first write a 300-400 word essay about why they are studying engineer, conduct a peer-edit to reduce the word count to approximately 150 words, and finally, present their One-Minute Engineer orally in front of their classmates. This assignment helps students articulate why they want to be an engineer while honing their technical writing and presentation skills. In their written drafts and presentations, students were required to reflect on at least one of their top-five Strengths.

\section{Results and Discussion}

\section{Team formation}

In general, the four domains of Strengths are not evenly represented in student (or other)

populations (Figure 2). Our engineering students are even more biased toward the Executing and Strategic Thinking domains than the other populations examined. Our engineering students show a lower occurrence of Relationship Building Strengths. Yet, Relationship Building is only 20\% less frequent than Executing Strengths in our Engineering students. The influencing domain is present $60 \%$ less often than Executing among our students. The low occurrence rate for the Influencing domain is common among all three populations.

We attempted to have CATME distribute students into teams with diverse sets of Strength domains. However, many similar patterns emerged within our student population, leading to less than the mathematically ideal distribution for this factor. With several competing optimization objectives, the CATME score for this factor was not strong. However, we conducted a post hoc 
inspection to ensure every team has at least one member with strength in each of the four domains.

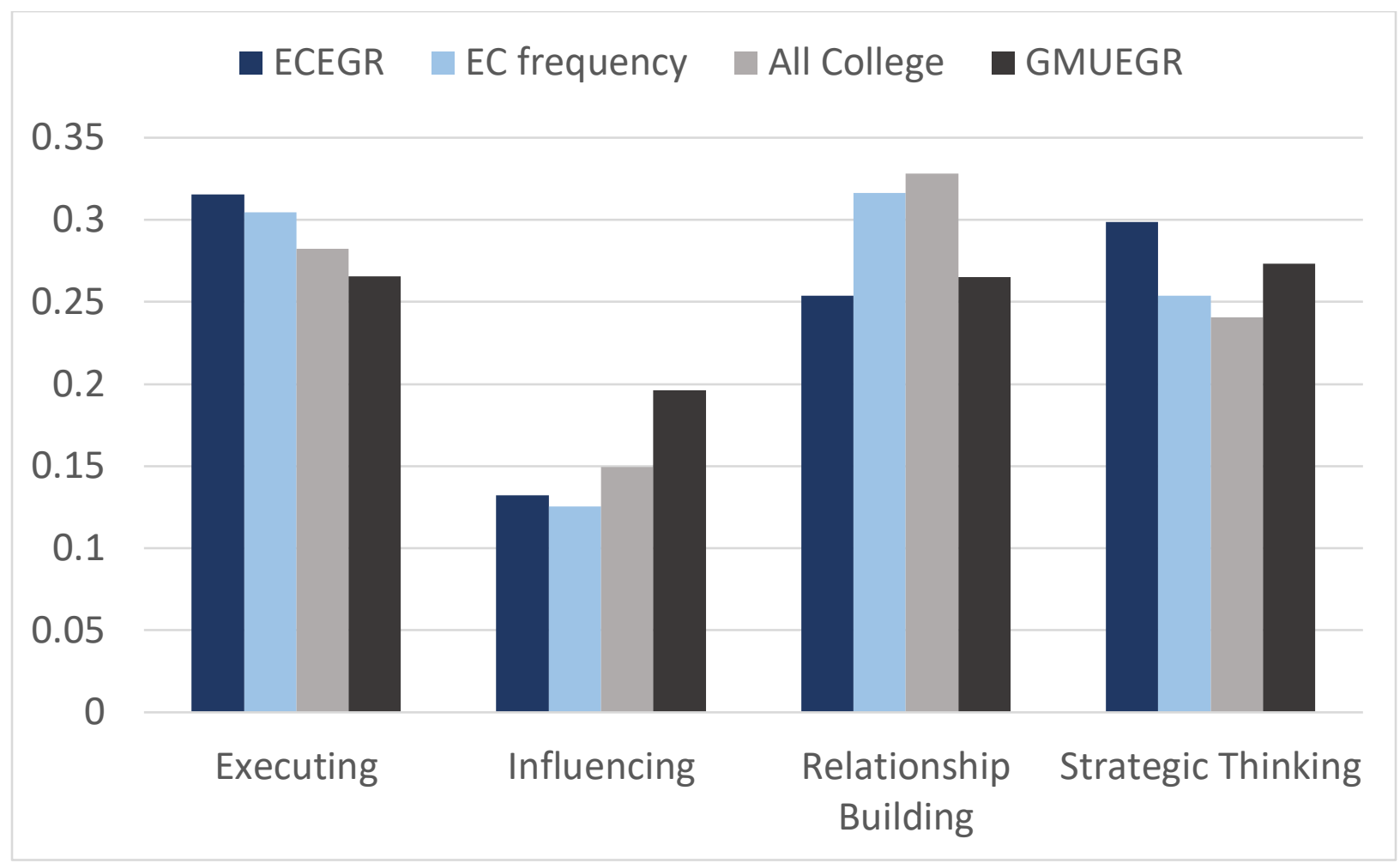

Figure 2: Relative frequency of domains among Elizabethtown College Engineering students. Comparison values indicate difference between ECEGR and the general population at Elizabethtown College, college students across the USA [15], and values from engineering students at another institution [14]

Since the talents in the Influencing domain are least frequent, we have found that students possessing those Strengths are very valuable to their teams. These are often students that excel in presentations and selling their teams' ideas to clients. Students with Relationship Building Strengths are also very valuable to their teams in managing conflict and bringing out the best in all team members.

Distribution of our engineering students Strengths as compared to other populations Looking at individual Strengths, we observe a few unique characteristics for the Elizabethtown College Engineering students (Figure 3; Figure 4; Figure 5; Figure 6). First, while generally Elizabethtown College students are similar to the national averages, we find that the Intellection (20\%) and Restorative (34\%) Strengths occur with a frequency rate 9 points (occurs in 9 more students out of every 100) higher than in general among US college students (11\% and 25\% respectively). Developer occurs at a rate 6 points higher at Elizabethtown College. All other differences are less than 5 points different. 
Comparing our Engineering students to the overall Elizabethtown College student body reveals even larger differences. Engineering students (32\%) display a 23-point higher likelihood to have the Analytical strength than non-engineering students (9\%). The Strategic strength is 16 points higher in the engineering students (32\% vs. 16\%). Input (10\% vs. $24 \%$ ) and Intellection (7\% vs. $20 \%$ ) are more than 10 points lower in the engineering students. Several other Strengths show moderate differences with a 5-10 point difference with the Elizabethtown college-wide frequency rates: higher for engineers: Focus, Competition, Achiever; lower for engineers: Developer, Woo, Empathy, Communication, Harmony, and Restorative.

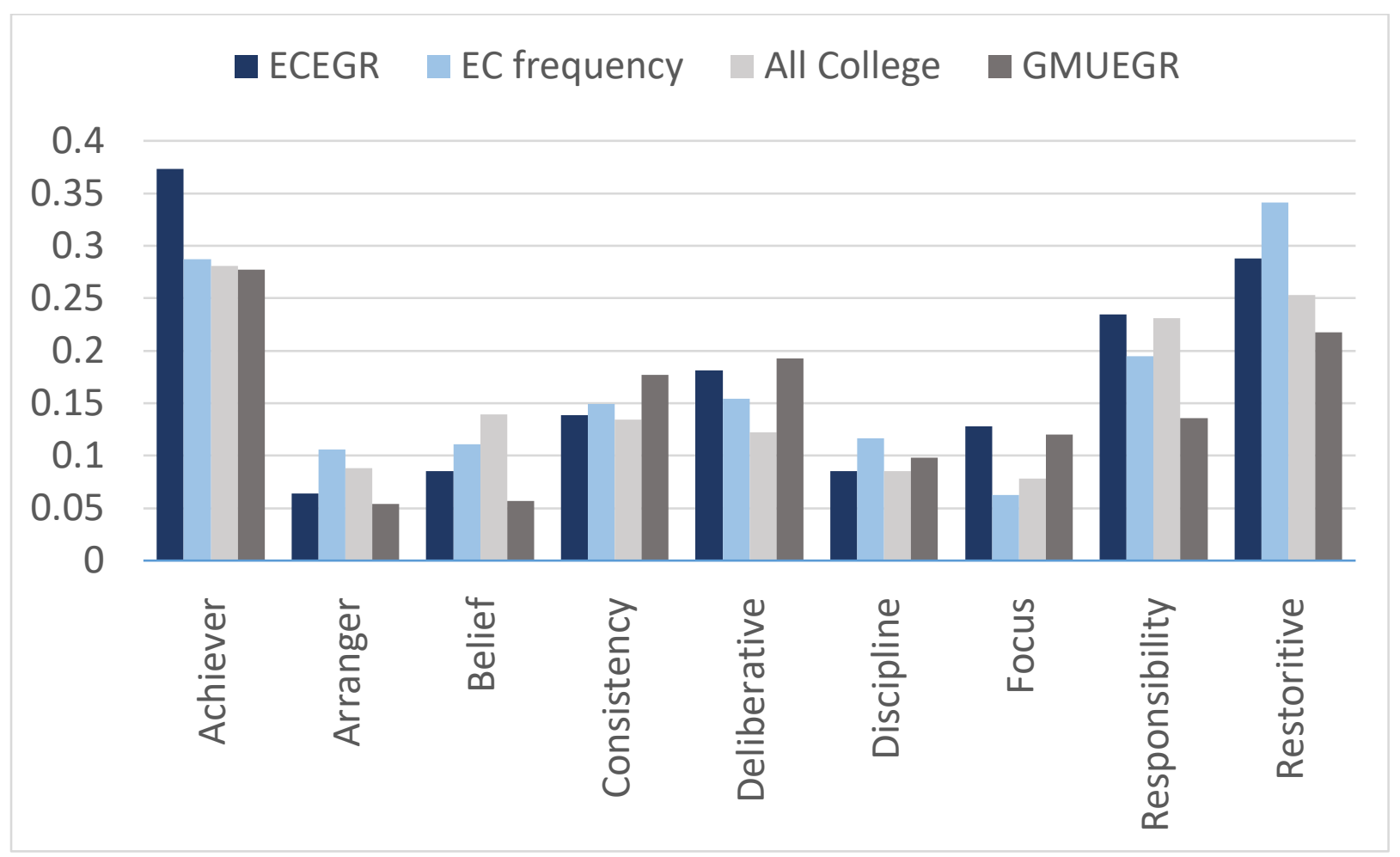

Figure 3: Rate of occurrence of each of the 9 Executing Strengths among Elizabethtown College Engineering students. Comparison data shows a difference between ECEGR and the general Elizabethtown College student population, average values from college student populations across the USA [15] and values from engineering students at another institution [14].

We also found that our engineering students had a somewhat different distribution of Strengths than engineering students from another institution, Grant MacEwan University [14]. The Elizabethtown College Engineers had a 14-point higher occurrence of the Strategic strength (32\% vs. 18\%). Several other Strengths differed in the 5-10 point range, with Responsibility, Achiever, Analytical, Positivity, Restorative, and Learner occurring at a higher rate for the Elizabethtown College students. Individualization, Competition, Command and Ideation Strengths occurred at higher rates among the Grant MacEwan University students. 


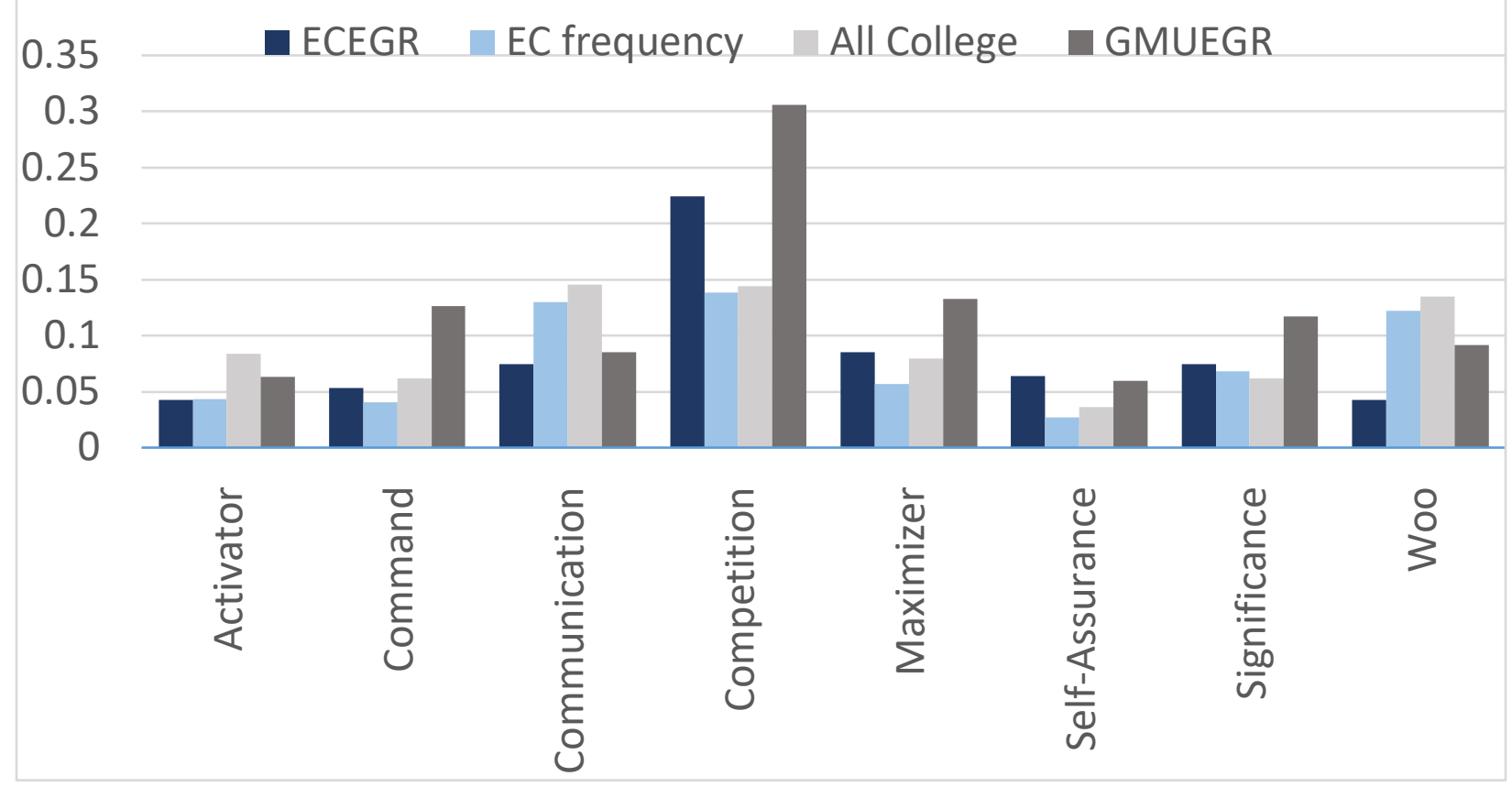

Figure 4: Rate of occurrence of each of the 8 Influencing Strengths among Elizabethtown College Engineering students. Comparison data show a difference between ECEGR and the general Elizabethtown College student population, average values from college student populations across the USA [15], and values from engineering students at another institution [14].

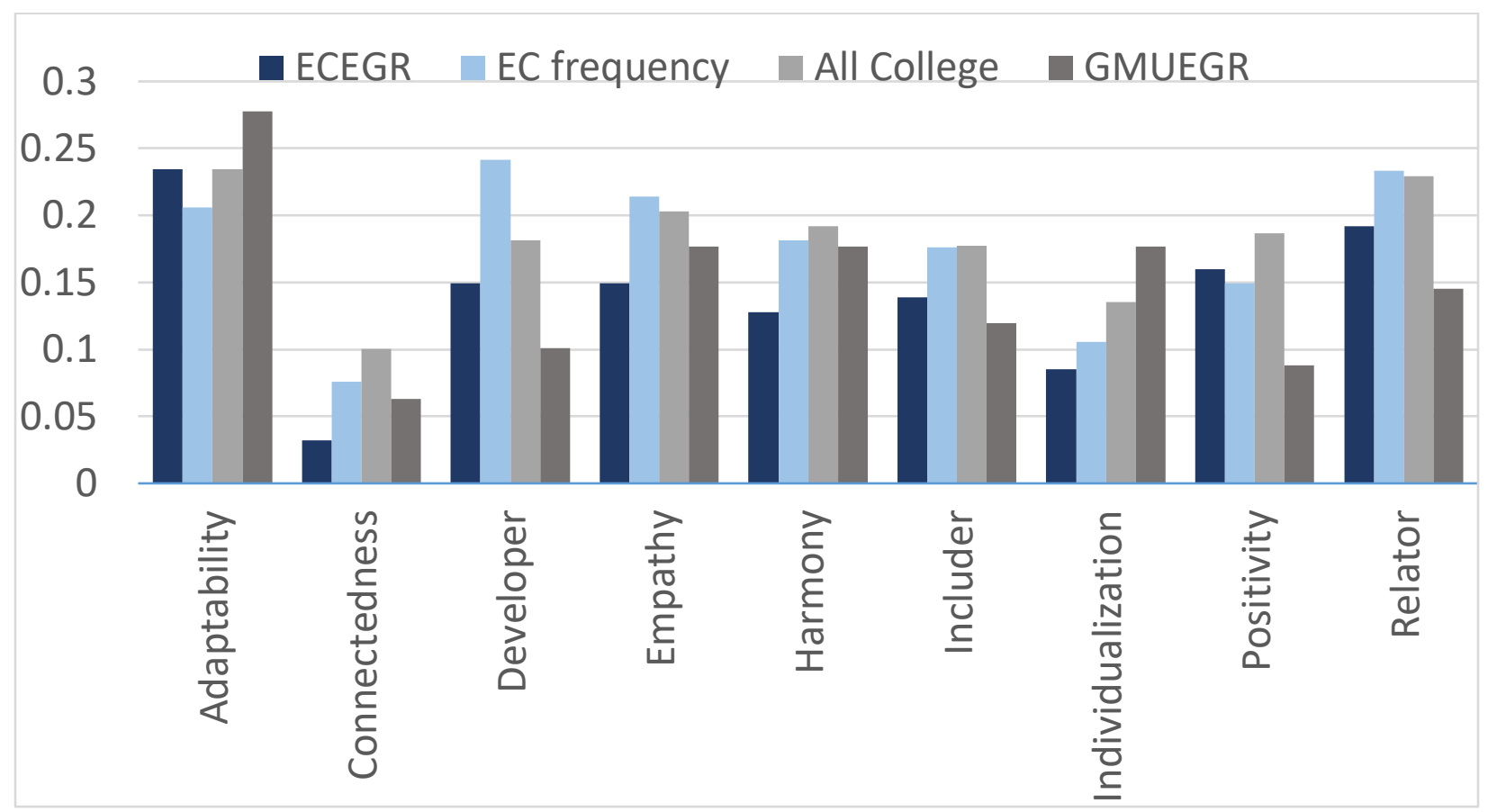

Figure 5: Rate of occurrence of each of the 9 Relationship Building Strengths among Elizabethtown College Engineering students. Comparison data shows a difference between ECEGR and the general Elizabethtown College student population, average values from college 
student populations across the USA [15], and values from engineering students at another institution [14].

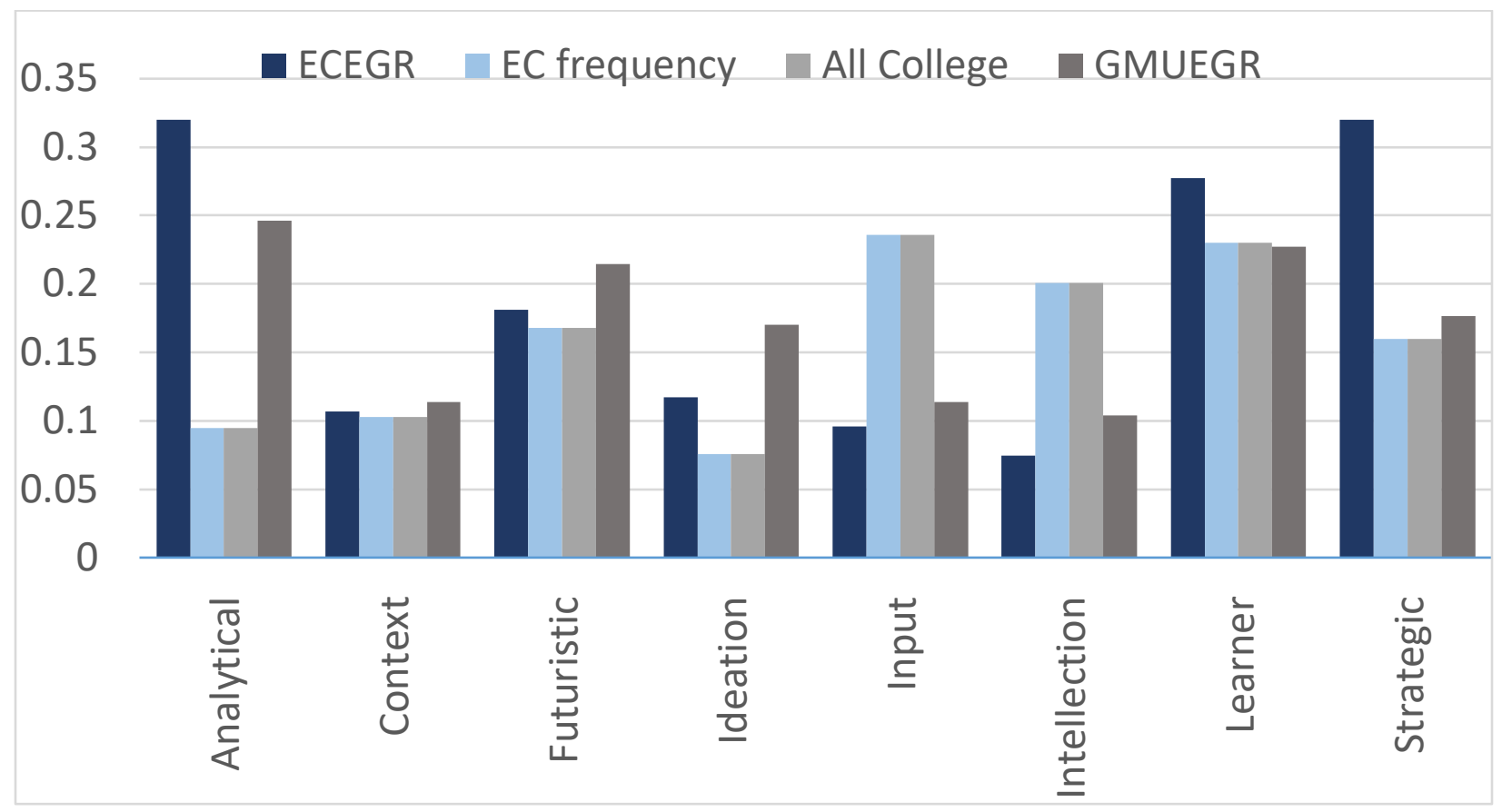

Figure 6: Rate of occurrence of each of the 8 Strategic Thinking Strengths among Elizabethtown College Engineering students. Comparison data shows a difference between ECEGR and the general Elizabethtown College student population, average values from college student populations across the USA [15], and values from engineering students at another institution [14].

These results help us better understand our students and design educational pedagogies accordingly. Our engineering students were found to be high in the achiever Strength indicating that they tend to be goal-focused. With both the Elizabethtown College and Grant MacEwan University students, competition was also found to be well-represented showing that engineering students tend to be more competitive than the general population. Team projects and other learning activities with clear goals and competitive components resonate with many of our students.

Executing and Strategic Thinking were heavily represented talent domains among engineering students. Influencing and Relationship Building were less represented. Therefore, when performing the team sorting analysis, students with Relationship Building Strengths were often the only student with that strength domain in their teams. In both the Elizabethtown College and Grant MacEwan engineering students, the developer strength was underrepresented. Developers are good at seeing the potential bringing out the best in others. With this strength underrepresented among engineering students, teams may need additional support to help manage the underperformance of individuals. Additionally, intellection and input were also underrepresented. We see this play out in the depth of thought students collectively bring to reflective work. Students also have a tendency to want to jump to solutions and do not 
instinctively take the time to gather appropriate information in order to inform their design decisions. Therefore, we need to design structures to encourage more introspective reflection and taking the time to gather background data.

\section{Team Contract}

As part of semester-long group assignments, students were required to complete team contracts detailing communication among group members, conflict resolution, and work allocation.

Students were not explicitly required to address their top-five Strengths. However, nearly all the teams used Strengths-based language when describing the approach to assigning team members' roles and responsibilities. Names in the following quotes were changed to protect students' privacy.

"...We discussed strengths and used them to determine the roles that each individual should take in the group..."

Other teams more generally considered their teams' mapping across the different domains of Executing, Influencing, Relationship Building, and Strategic Thinking:

"Our rationale for selecting leaders and individuals for specific tasks rely on our strengths and abilities to communicate. We are all good executors, so completing tasks should not be an issue. If there is (sic) any tasks requiring intense strategic thinking, [Kelly] can handle this. We all have relationship skills, so we do not worry about communication amongst the team and other stakeholders."

Some teams recognized the value in choosing roles based on Strengths as a means of improving team morale, productivity, and quality:

"We selected the people for the described roles based on their aptitudes, experiences, personalities, likes and dislikes and overall contribution to the group dynamic. By doing so, we ensure that each member will be satisfied with their role and contributions to the overall group, in addition to producing the best possible product."

"We will make sure that each team member is working to their strengths so that their work is of the highest quality."

Other teams went further with their discussion of Strengths and role assignments by highlighting individual team member's Strengths and explaining how they can contribute best to the team based on that particular Strength by providing specific examples:

"...[Erin's] positivity strength will prevent the team from becoming overwhelmed when due dates approach."

“[Wesley's] responsibility strength will help the team make sure all assignments are turned in on time. [Leon's] strength of arranger will help him organize the documents and write the best that could be done." 
"... [Caitlyn] is in charge of keeping documents because responsibility is one of her top five strengths...[Kyle] is a competitive person and this will help our team to turn in the best work possible and strive for success..."

"We chose to give me the task of the recorder because I am an includer. Therefore I want to make sure that everyone is on the same page with what is going on in every aspect of the project. Also, I am strategic so writing things out allows me to organize and visualize everything in a more complex way. Being able to see write everything allows me to strategically plan out and keep up with the rest of the group."

"I am resotarive (sic) and adaptable, so I can better help the group get back to the task at hand when issues or conflicts arise[...]I have the strength of developer, so I can encourage people to do their best work and help by assigning jobs that highlight their strengths."

"I am an achiever and like to complete work most effectively and to the best of my ability. This way I will double check the work that we have done to make sure everything is completed. Since I have a lot of previous experience will excel I can organize data effectively and neatly. I also have the strength of focus so I stay focused on my tasks and don't allow distractions to deter me from the task the group needs to complete."

"I am responsible so therefore I took up the job of submitting things to canvas. I always hand in my work on time and double check everything when I do, so I figured it would be a good thing for me to control handing in the material."

Some teams assigned roles and responsibilities considering Strengths and skill sets.

"The selections and assignments being made are done based on individuals' strengths as denoted by Gallup Strengths Finder. Self-professed strengths are also taken into account. Other important factors are roles held in the previous semester. Prior knowledge and affinity for learning about computer programs such as MatLab and CAD are also important."

"Members of the group will be given specific roles and areas of leadership. These roles will be based off of each individual's top five strengths and self identified (sic) weaknesses. With this information, each person will be given an appropriate role. Based on the role the member is given, the member is expected to obtain this role for the entirety of the semester."

\section{One-Minute Engineer}

In the case of the One-Minute Engineer assignment, students were explicitly asked to discuss at least one of their Strengths when reflecting on why they want to pursue engineering.

"One benefit I have experienced of having input as a strength, is my ability to remember facts, definitions, and methods of doing tasks. I am able to recall necessary information, apply it to new situations and problems, and study for less time than my peers." 
"One of my strengths is 'adaptability, ' which works well for engineering. Adaptability helps engineers when at a dead end and a fresh perspective is needed since they are always looking for new ideas to help make projects better."

"I like to solve problems and that is why Restorative is one of my strengths. Whenever my computer has a problem, I want to know what caused the problem so I can solve it."

Some students merely listed and defined some of their top Strengths, but failed to connect the strength to success in engineering.

"My top strengths are "Ideation", which is the fascination of ideas and discovering how things work, and an "Arranger", meaning I like to figure out the best way to get projects done. These strengths will help me in the field of engineering."

At various points in the semester, students are required to evaluate their teammates using CATME's Peer Assessment tool. Students have the option of providing confidential comments to the instructor. In several cases, students displayed evidence of valuing their teammate's diverse strengths and skills.

"Everyone on the team compliments (sic) one another in different ways. We all work together to accomplish similar goals and I believe we can all do each others (sic) tasks just as efficiently as the other group members. Each member does their own work and nobody is stuck with the majority."

"I am very satisfied with this team because each individual has their own strong points so together I believe we can work well and even better in the future."

"I have enjoyed working with my team so far and do not believe we have had any problems. Personally, I feel I am a bit slow to grasp onto things at times, which makes it difficult for me to get things done on time, or even to do as much as the rest of the team. However, my teammates have been very encouraging and good at communicating and we have all been able to pull through. We are very well organized. [Ben] and [Kristen] in particular have been very good at completing work fast an efficiently and communicating to the rest of the group. [Emily] has also been especially fast. I have been happy to work alongside [Rob] as well. He has greatly encouraged me, which has helped me do better and ultimately feel like part of the team[...]I feel I am becoming more confident and am hoping I will improve more."

\section{Conclusions}

The StrengthsFinder results mirrored those of the general population and first-year engineering students at Grant MacEwan University in most categories, but a few talents stood out as unique. In particular, the Strengths of Achiever, Analytical, and Strategic had stronger representation among the engineers at our institution. 
Implementing this approach was valuable for creating teams with diverse talents. Students with Strengths falling in the Influence or Relationship-Building domains were considered assets, due to their less frequent representation. They embraced the concept by allocating roles and responsibilities using Strengths and indicating their appreciation of one another's talents as evidenced by team contracts and peer evaluations. Conducting the StrengthsFinder analysis also helped us better understand and relate to ItE the student population. In several cases, we specifically formed teams to address some unique challenges posed by students with social communication disorders, paring these students with Strength in Empathy or Developer.

We found this exercise to be meaningful for first-year engineering students as it sets the stage for positive team dynamics in future engineering courses. With repeated exposure, students become more familiar with Strengths-based language and can better articulate what they can offer to their teams. As they learn to work with students possessing a wide variety of Strengths, they also enhance skills critical for success on diverse teams. Additionally, academic advisors were able to use Strengths as a framework for discussing students' academic progress and professional development. As one example, students cultivate professional development plans originally drafted in the ItE courses. They list their top-five Strengths on the top of the plan and develop strategies for achieving professional goals utilizing those strengths. Upon graduation, these Strengths-based plans along with reflections on their personal strengths provide a powerful tool for students preparing for interviews and mentors when writing recommendations and references. Another unexpected benefit was identifying strong candidates for a Family Business and Entrepreneurship minor offered by the college. With a record of the Strengths profile of all students, we could flag students who might thrive in this programs.

In both the One-Minute Engineer and the Team Contract assignment we have observed improved student confidence. Students learn how others with all types of strengths bring their unique and valuable talents to engineering work. They become comfortable in their own "skin" claiming an engineering career path as their own from their personal position of strength.

By using Strengths in our ItE courses, we observed population differences that we find interesting and meaningful. This knowledge provides us with an institutional self-awareness that helps us better understand our students on an individual as well as collective level. By intentionally communicating the importance of diversity, we hope students internalize the message that their differences and unique attributes are celebrated. Thus, we seek to improve self-efficacy, retention in the engineering program, and classroom performance through a culture of Strengths.

In the future, we plan to more overtly incorporate Strengths in teaching, advising, and project mentoring. We look to create structures that support students with a diversity of strengths in traditional quantitative engineering courses. Also, we plan to more intentionally use Strengths in our academic advising, specifically, by helping students use their strengths to find purpose and meaning in their professional path. Highlighting student strengths can increase their personal expectancy of success and therefore enhance motivation for their studies and professional work [19].We also can use Strengths to help students achieve specific professional goals. For 
example, students know that networking is important but tend to shy away from networking opportunities if they are more introverted. The advisor can provide strategies on how to leverage the student's individual Strengths to accomplish that particular goal: for example, with a Strength of Competition - think of trying to gather more new contacts than your roommate. In projects, we will continue to emphasize how all students have unique talents to bring to their teams.

\section{References}

[1] T. Rath, StrengthsFinder 2.0, New York: Gallup Press, 2007.

[2] M. L. Loughry, M. W. Ohland and D. J. Woehr, "Assessing teamwork skills for assurance of learning using CATME team tools," Journal of Marketing Education, vol. 36, pp. 5-19, 2013.

[3] S. Zemke and D. Elger, "Curricular elements that promote professional behavior in a design class," in ASEE Annual Conference Proceedings, Chicago, 2006.

[4] J. Asplund, S. Agrawal, T. Hodges, J. Harter and S. J. Lopez, "The Clifton StrengthsFinder 2.0 Technical Report," Gallup Inc., Washington DC, 2014.

[5] S. J. Lopez and M. C. Louis, "The Principles of Strengths-Based Education," Journal of College and Character, vol. X, no. 4, pp. 1-8, 2009.

[6] T. Rath and B. Conchie, Strengths Based Leadership, New York: Gallup Press, 2009.

[7] N. F. Jackson and S. Magun-Jackson, "Improve Your Strengths and Manage Your Weaknesses: Using the StrengthsFinder Profile in Team Development," in ASEE Annual Conference Proceedings, Nashville, 2003.

[8] Gallup, "The Clifton StrengthsFinder and the Myers-Briggs Type Indicator," Gallup Inc., Washington DC, 2008.

[9] G. M. Rogers and J. K. Sando, "A Qualitative, Comparative Study of Students' Problem Solving Abilities and Procedures," in ASEE Annual Conference Proceedings, Washington, DC, 1996.

[10] J. D. Vernon, L. A. Meadows and S. Edington, "Educating the Whole Engineer: Transforming an Introductory Engineering," in ASEE Annual Conference Proceedings, Seatle, 2015.

[11] S. H. Gleixner, K. Casey, J. Tuberty, S. Latic, P. Backer and E. Allen, "EXCEED: Excellence in Your Engineering Education Summer Transition," in ASEE Annual Conference Proceedings, Atlanta, 2003.

[12] S. Lorimer and J. A. Davis, "Using Strengths of First-Year Engineering Students to Enhance Teaching," in ASEE Annual Conference Proceedings, Seattle, 2015.

[13] J. S. Shelley, K. W. Santarelli, C. R. Warren and A. Bahrami, "Observations of the Application and Success of Leadership Development Tools," in ASEE Annual Conference Proceedings, Columbus, 2017.

[14] S. Lorimer and E. Elford, "StrengthsQuest for Engineers," in ASEE Annual Conference Proceedings, San Antonio, 2012.

[15] Gallup, StrengthsQuest Team Frequency, Washington DC: Gallup Inc., 2017. 
[16] R. A. Layton, M. L. Loughry, M. W. Ohland and G. D. Ricco, "Design and validation of a web-based system for assigning members to teams using instructor-specified criteria.," Advances in Engineering Education, vol. 2, no. 1, pp. 1-28, 2010.

[17] Transferable Integrated Design Engineering Education, Teamwork Assessment for Capstone Engineering Design, www.tidee.org [no longer available], 2008.

[18] Gallup, Team Talent Map, Washington DC: Gallup Inc., 2013.

[19] C. S. Hulleman and K. E. Barron, "Motivation interventions in education: Bridging theory, research, and practice," in Handbook of Educational Psychology, 3rd Edition, New York, Routledge, Taylor and Francis, 2015, pp. 160-171. 